\title{
Relevance of infection with human papillomavirus: The role of the p53 tumor suppressor protein and E6/E7 zinc finger proteins (Review)
}

\author{
BRANISLAV RUTTKAY-NEDECKY ${ }^{1,2}$, ANA MARIA JIMENEZ JIMENEZ ${ }^{1,2}$, LUKAS NEJDL ${ }^{1}$, \\ DAGMAR CHUDOBOVA ${ }^{1}$, JAROMIR GUMULEC ${ }^{2,3}$, MICHAL MASARIK ${ }^{2,3}$, \\ VOJTECH ADAM $^{1,2}$ and RENE KIZEK ${ }^{1,2}$
}

\footnotetext{
${ }^{1}$ Department of Chemistry and Biochemistry, Faculty of Agronomy, Mendel University in Brno, CZ-613 00 Brno;

${ }^{2}$ Central European Institute of Technology, Brno University of Technology, CZ-616 00 Brno;

${ }^{3}$ Department of Pathological Physiology, Faculty of Medicine, Masaryk University, CZ-662 43 Brno, Czech Republic
}

Received July 8, 2013; Accepted August 12, 2013

DOI: 10.3892/ijo.2013.2105

\begin{abstract}
Human papillomaviruses (HPV) are small circular, double-stranded DNA viruses infecting epithelial tissues. HPV types can be classified both as high-risk or low-risk. Of the more than 120 different identified types of HPV, the majority are involved in infections of the genital tract, cancer of the cervix, vulva, vagina and penis, and of non-anogenital localizations, such as the head and neck areas. From the point of view of the infection, human papillomaviruses have developed several molecular mechanisms to enable infected cells to suppress apoptosis. This review provides a comprehensive and critical summary of the current literature that focuses on cervical carcinoma and cancer of the head and neck caused by HPV. In particular, we discuss HPV virology, the molecular mechanisms of carcinogenesis, the role of the tumor suppressor protein p53 and the E6/E7 zinc finger proteins. Classification of HPV according to diagnosis is also described.
\end{abstract}

Correspondence to: Professor Rene Kizek, Department of Chemistry and Biochemistry, Mendel University in Brno, Zemedelska 1, CZ-613 00 Brno, Czech Republic

E-mail:kizek@sci.muni.cz

Abbreviations: AZF, artificial zinc fingers; AZPs, artificial zinc finger proteins; BPV, bovine papillomavirus; EGF, epidermal growth factor; HNSCCs, head and neck squamous cell carcinomas; HPV, human papillomavirus; MT, metallothionein; NPC, nasopharyngeal cancer; ORF, open reading frame; $\mathrm{pRb}$, retinoblastoma protein; SILs, squamous intraepithelial lesions; SCCs, squamous cell carcinomas; SCJs, squamocolumnar junctions; TGF- $\alpha$, transforming growth factor- $\alpha$

Key words: human papillomavirus, head and neck cancer, metallothionein, protein $\mathrm{p} 53$, zinc finger proteins

\section{Contents}

1. Introduction

2. Types of HPV head and neck cancers

3. HPV virology

4. Molecular mechanism of HPV carcinogenesis

5. Interaction of HPV E6 and $\mathrm{p} 53$ proteins

6. HPV E6/E7 proteins and zinc fingers

7. Metallothionein in head and neck cancer

8. Zinc, zinc fingers, p53 and metallothionein - is there any connection with HPV?

\section{Introduction}

Human papillomaviruses (HPVs) are a large family of small double-stranded DNA viruses infecting squamous epithelia (1) and causing papillomas in most mammals $(2,3)$. The viruses are absolutely species-specific (1) and they have been detected in a variety of mammalian and avian species including humans, parrots, canines and felines (4). In addition, HPV has been accepted as an etiologic agent for cervical carcinoma, whereas the first association with head and neck cancer was published in 1985 (5). HPV was also shown to play a role in the pathogenesis of a subset of head and neck squamous cell carcinomas (HNSCCs) (6). HNSCCs belong to majority of head and neck malignancies (7-9). The term head and neck cancer includes malignancy in an area that comprises the skin, oral cavity, salivary glands, lip, pharynx, larynx, nasal cavity, paranasal sinuses and soft tissues of the neck and ear (7). Almost 650,000 patients worldwide are diagnosed with head or neck cancer each year and 350,000 patients die of this disease (5) as this cancer is the sixth most prevalent type of cancer worldwide. The ratio of males to females is approximately 2:1 (7).

In head and neck cancer patients, two types of clinical precancer lesions have been established: white lesions (leuko- 
plakia) and reddish lesions (erythroplakia) (10). Precancerous lesions of the oral mucosa are epithelial changes that are able to undergo malignant transformation more likely than normal tissue at other mucosal sites. HPV is also a central causative agent in cervical carcinogenesis (11). HPV selectively infects the epithelium of the skin and mucous membranes. Specific HPV types are associated with squamous cell carcinoma, adenocarcinoma, and dysplasias of the cervix, penis, anus, vagina and vulva (12). A total of 150 HPV genotypes have been identified and fully sequenced (13-15). Determination of HPV genotype is based on the degree of homology within the L1 (major capsid protein) ORF (13). If the DNA sequence of the L1 ORF differs by more than $10 \%$ from the closest related known type, it is regarded as a novel type. HPV types associated with skin warts are for example HPV-1, -2 and -4 (16). A wide range of HPV types including HPV-5, -8, -9, -23 and -47 cause epidermodysplasia verruciformis lesions, which can be transformed to malignancy upon exposure to ultraviolet light (17). The largest subgroup is represented by HPV types infecting mainly mucosal surfaces of the genital and respiratory tracts. More than 40 of the identified HPV types belong to this group (13). HPV types are often referred to as 'low-risk' or 'high-risk' based on their potential for oncogenesis. The high-risk HPV types include HPV-16, -18, -31, -33, -35, -39, $-45,-51,-52,-56,-58,-59,-68,-73$ and -82 . The low-risk HPV types cause especially benign lesions affecting the anogenital areas, such as genital warts (condylomata), low-grade squamous intraepithelial lesions (SILs) of the cervix, and laryngeal papillomas. These low-risk types include HPV-6, -11, -40, -42, $-43,-44,-53,-54,-61,-72$ and -81 (18).

\section{Types of HPV head and neck cancers}

There are different types of HPV head and neck cancers according to the location in the human body (7). In the following section, several types of HPV are defined and their characteristics are given.

Oral cavity, salivary glands and lips. The verrucous carcinoma is a variant of HNSCCs found in the oral cavity. This carcinoma has been recognized as a locally invasive, non-metastasizing squamous cell carcinoma (SCC) with locations in the oral cavity, lips and larynx as well as in the genital tract (19). The most common HPV types in oral carcinomas are HPV 16, 33 and 82 (20).

Laryngeal area. The number of copies of HPV DNA is low in head and neck carcinomas excepting tonsillar carcinoma, which indicates a non-clonal association of these tumors. The HPV detection rate of $51 \%$ in tonsillar carcinomas is among the highest of any extragenital human malignancies $(21,22)$. Antibodies against HPV proteins E6 and E7 are present in $65 \%$ of HPV DNA-positive cancers (oro-pharynx and tonsils), but only in $13 \%$ of HPV-positive oral cancers (23). The larynx is among the most significant anatomic sites in terms of HPV involvement, exceeded perhaps only by the genital tract and skin infections in clinical importance. This is because that HPV infection is the etiological agent of a clinically significant disease known as laryngeal papilloma (papillomatosis) $(24,25)$.
Nasal cavity and paranasal sinuses. The HPV DNA in malignant lesions of the nasal cavity and the paranasal sinuses produce polyps, inverted papillomas and squamous cell carcinomas. Squamous cell carcinomas are the most frequent malignant tumors in this region. Report on malignant transformation of benign lesions to sinonasal carcinomas has been published. The study focused on paranasal sinuses because this area is independent of tobacco and especially alcohol exposure (26). The coexistence of two different epithelia in sino-nasal papillomas and carcinomas (columnar cells and stratified squamous epithelium) creates squamocolumnar junctions (SCJs) at multiple sites in the respiratory tract, entities that are thought to be a prerequisite for the spreading HPV infections in this region (27-29).

\section{HPV virology}

HPVs are small, non-enveloped double-stranded DNA viruses. The HPV has a diameter of 55 nanometers and a genome consisting of a double-stranded circular DNA of approximately 8,000 nucleotide base pairs associated with histones. This genome is enclosed in an icosahedral capsid shell comprised of major and minor capsid proteins (30). The genome that can be divided into 3 domains: an early region with 6 open reading frames (ORFs) E6, E7, E1, E2, E4 and E5; a late region with 2 ORFs, L1 (the major capsid protein) and L2 (the minor capsid protein); and a non-coding regulatory region (NCR) of approximately $1 \mathrm{~kb}$, is shown in Fig. 1 . The three regions are separated by polyadenylation sites, early AE and late AL.

The E1 protein binds to the origin of replication (31). The E2 ORF encodes protein that act as a transcriptional activator of HPV gene expression in both normal and immortalized keratinocytes $(32,33)$. The E2 proteins bind to E1 and stimulate viral DNA replication (34). The E4 is expressed as a late gene with a role in the productive infection. E5 protein stimulates the transforming activity of the epidermal growth factor receptor resulting in the increased cell proliferation $(16,35)$. The E6 protein of HPV-16 is a small polypeptide of approximately 150 amino acids that contains two zinc-binding domains (36). It is a transforming protein and stimulates p53 degradation (37). The HPV-16 E6 protein also activates telomerase, an enzyme that maintains the telomeric DNA at the ends of linear chromosomes $(38,39)$. Without telomerase, telomeres shorten upon each cell division, until they reach a critically short length. Beyond this point further division induces damage in the coding regions of the chromosome and causes cell senescence. Almost all human cancers and immortalized cell lines have highly active telomerase $(40,41)$. The E7 protein of HPV-16 is a small, nuclear polypeptide of 100 amino acids. Interestingly, the carboxyl-terminus of E7 contains a similar zinc-binding domain as does E6. E7 binds to retinoblastoma protein (pRb). Besides pRb, E7 also interacts with various other proteins, most of which are important regulators of the cell growth (42). The E7 protein induces abnormal centrosome duplication, resulting in multipolar, abnormal mitoses, aneuploidy and genomic instability (43). Both the E6 and E7 proteins play a role in the cell transformation and immortalisation $(16,44,45)$. The L1 and L2 late proteins form capsomers of the virus that encapsidate the viral DNA. The $\mathrm{L} 1$ is the major capsid protein and contains reactive 


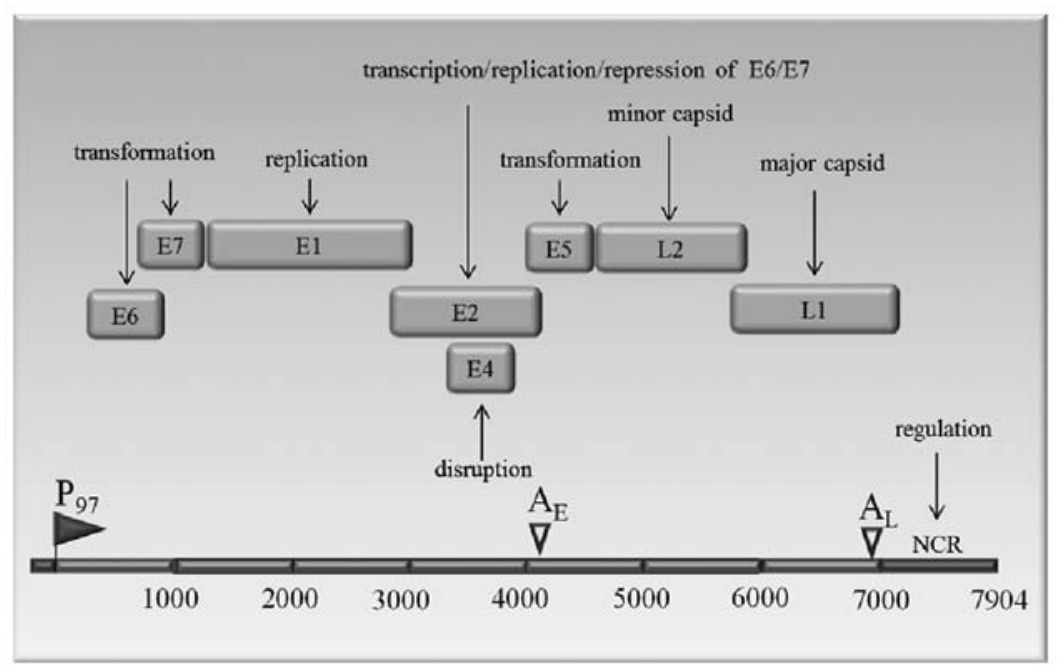

Figure 1. Genomic organization of the human papillomavirus type 16. ORFs deduced from the DNA sequence are designated E1 to E7, and L1 and L2. The non-coding region (NCR, also known as a long control region) is also shown. AE and AL indicate early and late polyadenylation sites. Adopted and modified according to Chen et al (16).

epitopes for type-specific neutralisation. The L2 protein is a minor component of the viral capsid $(24,46)$. HPV infects cells in the basal layer (stratum basale), below the surface of the epithelium and carries out an infection cycle that is closely tied to the differentiation program of the host cells (1).

\section{Molecular mechanism of HPV carcinogenesis}

Carcinogenesis is a multistep process associated with the accumulation of genetic alterations in cells (47). The cancer results from the accumulation of specific genetic mutations, many of which have now been identified. These mutations can cause an activation of genes that promote cellular proliferation or inhibit cell death (oncogenes), or they may inactivate genes that inhibit proliferation or promote cell death (tumor suppressor genes) (47). The proteins derived from various oncogenes, either cellular or viral, such as those of the polyomavirus SV40 $\mathrm{T}$ gene or the oncogenic human papillomavirus (HPV) E6 and E7 genes, will generally either increase the rate of cell division or inhibit programmed cell death (Fig. 2), thereby they will increase the risk of malignant transformation (48).

The molecular mechanism of HPV carcinogenesis can be explained by the regulation and function of the two viral oncogenes E6 and E7 (Fig. 3). These two genes of HPV 18 have been shown to possess transforming ability when transfecting into NIH 3T3 and Rat-1 cell lines (49). The E6 and E7 genes are under the regulation of the $\mathrm{E} 2$ gene product. The E2 gene is often the site for the integration, resulting in the disruption of the $\mathrm{E} 2$ gene and subsequent derepression of the E6 and E7 (50). The E6 gene product binds to the p53 tumor suppressor gene. The association of E6 with p53 leads to the specific ubiquitination and degradation of $\mathrm{p} 53$ protein (51). E7 targets another tumor suppressor protein, the retinoblastoma gene product ( $\mathrm{pRb}$ ) (52). Binding of the E7 to $\mathrm{pRb}$ alters its phosphorylation state and thereby functionally inactivates this protein, which, like p53, functions in the control of the
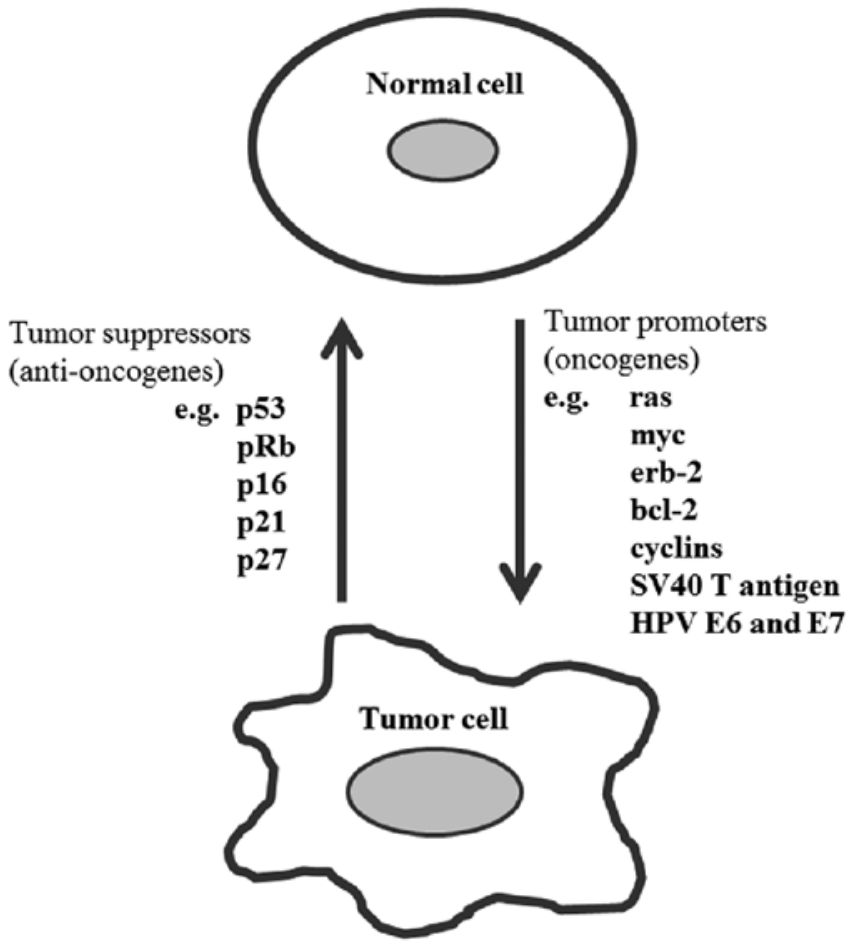

Figure 2. The protein products of the cellular tumor suppressor genes (anti-oncogenes). The proteins derived from various oncogenes, either cellular or viral [such as those of the polyomavirus SV40 T gene or the oncogenic human papillomavirus (HPV) E6 and E7 genes] will generally either increase the rate of cell division or inhibit cell death controlled by apoptosis. Adopted and modified according to Rose et al (47).

cell cycle. Normally, pRb binds the transcription factor E2F, which functions in the progression of the cell cycle from G1 to the $\mathrm{S}$ phase. The binding of $\mathrm{E} 7$ to $\mathrm{pRb}$ results in creation of an inactive E7-pRb complex; on the other hand, disrupted binding of $\mathrm{E} 2 \mathrm{~F}$ to $\mathrm{pRb}$ allows $\mathrm{E} 2 \mathrm{~F}$ to bind DNA and induce the cell growth and proliferation $(53,54)$. 


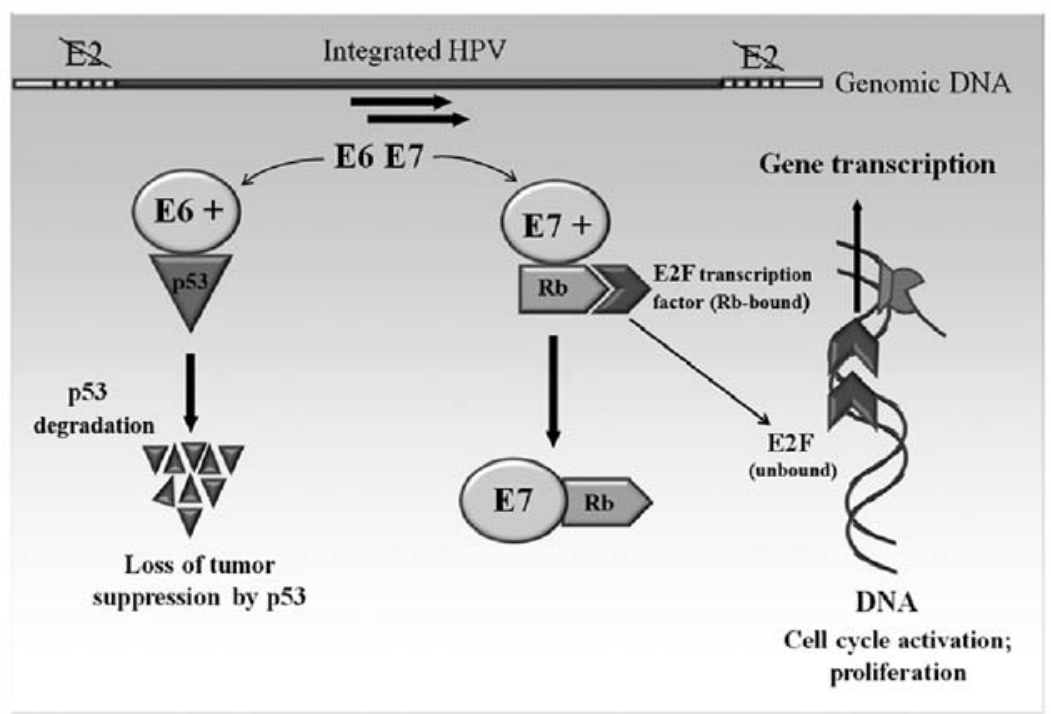

Figure 3. HPV-induced oncogenesis: cellular events. E6 binds to p53 and induces its degradation. E7 binds the Rb gene product and causes the transcription factor E2F-1 to become unbound and free to induce the cell cycle activation/proliferation. Adopted and modified according to Janicek et al (11).

Many oncogenes encode growth factors that stimulate proliferation of keratinocytes including transforming growth factor- $\alpha$ (TGF- $\alpha)$ and epidermal growth factor (EGF). Both proteins are frequently overexpressed in squamous cell carcinomas (SCC) of the head and neck, particularly of the oral cavity. Overall, approximately half of all the cancers of the mucosa of the head and neck are believed to contain mutations in a specific region of the $\mathrm{p} 53$ gene (55). Disruption to the function of p53 appears to be an early event in the head and neck oncogenesis and has been linked to exposure to mutagens, such as benzopyrenes, in tobacco. The inactivation of the product of the retinoblastoma gene (pRB), although it is less common than the p53, malfunctions in SCC of the head and neck (44). Although the significance of the p53 and $\mathrm{pRb}$ has been known for many years, the recent finding that malfunction of other genes controlling the cell cycle can lead to malignant transformation represents an important advance in the cancer biology (47).

\section{Interaction of HPV E6 and p53 proteins}

The p53 is a tumor suppressor gene and a key regulator of the cell proliferation. Due to its central role in the regulation of the cell cycle, p53 is systematically dysregulated in cancers (56). The p53 protein is a multifunctional protein that consists of 393 amino acids (Fig. 4). The cellular MDM2 protein, first known as a transcriptional target of $\mathrm{p} 53$, has been found to act as an E3 ubiquitin-ligase, which transfers ubiquitin (Ub) onto $\mathrm{p} 53$, thereby targeting it to proteasome-mediated degradation $(57,58)$. The p53 tumor suppressor is the first described and best known target of HPV E6 (37). The presence of the E6 in the high-risk types of HPV interferes with this process, because E6 binds to both p53 and E6-associated protein ligase (E6AP), causing ubiquitinylation and the subsequent degradation of the $\mathrm{p} 53$. This degradation then prevents $\mathrm{p} 53$ from inducing either the growth arrest or apoptosis of infected cells (59). Papillomavirus E6 oncoproteins interact with target cellular proteins through a conserved binding motif containing the sequence LXXLL $(60,61)$. The cancer-associated human papillomavirus type 16 protein E6 binds to the LXXLL motif (LQELL) on the cellular E3 ubiquitin ligase E6AP (62).

Clinical correlations. Yu et al investigated the relation between high-risk HPV 16/18 infection and p53 mutation in lung carcinomas and its association with tumor behavior (63). The study indicated that mutation in the p53 and HPV $16 / 18$ infection might coordinate in the development of lung squamous cell carcinomas, and their coexistence is associated with poor prognosis. Within the group of lung squamous cell carcinomas, the p53 mutation rate was significantly higher in those with HPV infection $(78.1 \%)$ than that of the non-infected carcinomas (51.2\%, $\mathrm{P}=0.004)(63)$. Katori et al investigated the relationship between the expression of $\mathrm{p} 21$ and p53 proteins, HPV infection and malignant transformation in sinonasal-inverted papilloma (64). A significant decrease in expression of p21 and p53 was observed in HPV 16/18 positive sinonasal-inverted papilloma compared with HPV 16/18 negative sinonasal-inverted papilloma, which could be caused by the degradation of p53 in HPV infected sinonasal-inverted papilloma (64). Similarly, Fujita et al investigated HPV infection and the expression of p53 in verrucous carcinoma (VC) (65). The expression of p53 was correlated inversely with HPV infection. Oral VC tumorigenesis may involve the inactivation of p53, which is associated with HPV infection.

Therapy of HPV-related cancers. In order to develop a gene-specific therapy for HPV-related cancers, Reschner et al investigated a potential therapeutic strategy of the silencing of HPV16 E6 oncogene by using an E6-antisense oligonucleotide (E6-ASO) in a polyazaaromatic ruthenium (Ru-II) complex (E6-Ru-ASO) (66). This complex was able to crosslink irreversibly the targeted sequence under visible illumination. They demonstrated that E6-Ru-ASO induces a reactivation of $\mathrm{p} 53$, the most important target of E6, as well 


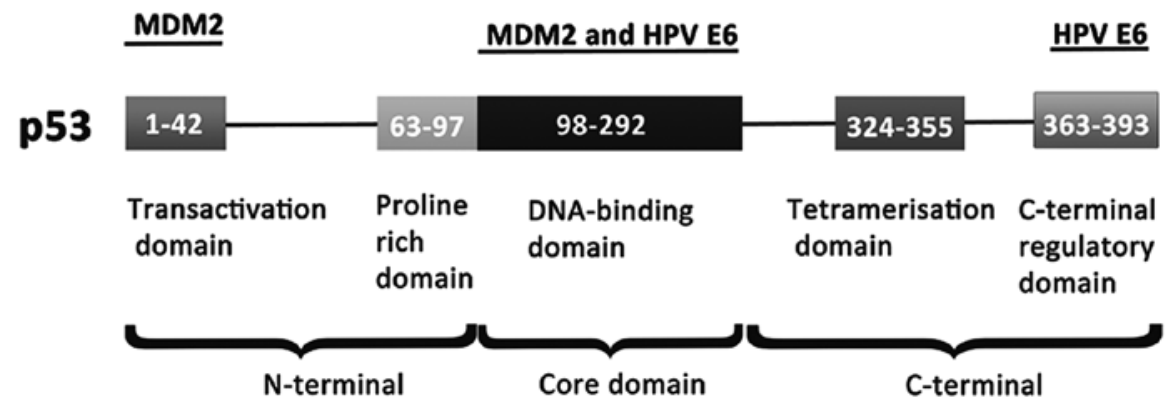

Figure 4. Localization of residues within the structure of the p53 core domain. Schematic view of the domain structure of the p53. The p53 protein that contains 393 amino acids comprises N-terminal transactivation domain, followed by a proline-rich region, a central DNA-binding core domain, a tetramerization domain and a regulatory domain at the extreme C-terminus. The regions of the possible interaction between p53 and MDM2 or p53 and HPV E6 are suggested. Adopted and modified according to Bernard et al (110).

as the inhibition of cell proliferation with a selective repression of E6 at the protein level after illumination in HPV16(+) SiHa cervical cancer cells (66). High-risk types of HPV, such as HPV16, have been detected in nearly all cases of cervical cancer. Therapies targeted at blocking the HPV16 E6 protein and its deleterious effects on the tumor suppressor pathways of the cell can reverse the malignant phenotype of affected keratinocytes while sparing uninfected cells. Togtema et al used sonoporation to deliver the HPV16 E6 antibody into the HPV16 positive cervical carcinoma derived cell lines (67). Delivery of the E6 antibody using sonoporation significantly restored expression of p53 in these cells, indicating that the antibody is able to enter the cells and remains active. Cervical cancer develops via progression from normal cervical epithelium through squamous intraepithelial lesions (SIL) to invasive cancer. Cervical cancer is associated with oncogenic human papillomavirus (HPV). The HPV E6 oncoprotein binds to the tumor suppressor gene product p53 under promotion of its degradation. The Arg allele of p53 containing Arg72 binds more ardently with HPV E6 than the Pro72 variant. In individuals that show HPV positivity, there was a significantly higher odds of progression from SIL to cervical cancer with the p53 Arg allele (68). Similarly, Chen et al examined p53 codon 72 polymorphism and expression of HPV oncoprotein in lung tumors from patients to determine the polymorphism of p53 codon 72 (69). The presence of HPV 16/18 DNA and the E6 protein was inversely associated with the expression of $\mathrm{p} 53$. The frequency of degradation of p53 protein was also much higher in HPV 16/18 E6-positive Arg/Arg (genotype at codon 72 of the p53 gene) lung tumors than in other groups (69).

\section{HPV E6/E7 proteins and zinc fingers}

The E6 protein of HPV16 consists of 158 amino acid residues and contains two (Cys-X-X-Cys) zinc fingers (70-72). This zinc finger sequence motif is unique for papillomavirus E6 and E7 proteins and includes numerous specific amino acid residues, highly conserved among all carcinogenic HPVs as well as among many animal and human papillomaviruses associated with benign lesions $(73,74)$.

Beerheide et al (72) investigated 36 compounds selected according to their structure for the ability to release zinc from the E6 protein of HPV16. Nine of the 36 tested compounds released zinc from E6, two of the nine compounds inhibited the interaction of E6 with E6-associated protein and E6-binding protein, and one of these two, 4,4'-dithiodimorpholine, selectively inhibited cell viability and induced higher levels of 553 protein (associated with the induction of apoptosis) in tumorigenic HPV-containing cells (72). This assay system may be useful in the development of drugs effective against cervical cancer, genital warts, and asymptomatic infections by genital HPVs.

Griffin et al (75) isolated an antibody fragment (GTE6-1) that binds to the protein E6 of HPV16 in its first zinc finger. The targeting of HPV16 oncogene may be an effective anticancer therapy (75). HPV E6 proteins have two mechanisms to abolish the function of $\mathrm{p} 53$, the repression of the transcriptional activity or eliminating the protein through the proteosome degradation pathway. The transcriptional coactivator $\mathrm{CBP} / \mathrm{p} 300$ interacts with HPV-16 E6 protein in the C-terminal zinc finger to repress the p53-dependent transcription (76).

The E6 oncoprotein of human papillomavirus (HPV) is critical in the development of cervical cancer. Jong et al have shown that HPV-16E6 (16E6) interacts with one of the DNA fragmentation factors (DFFs), DFF40, which mediates the DNA degradation during apoptosis (77). HPV-16 E6 interacts with DFF40 through its zinc finger motif 2 and a bridge section linking the two zinc finger motifs.

The similar domains of E6 and E7 proteins allow the formation of telomeric complexes that possess interesting biological activities (78). The mutations in the zinc finger domain of E7 do not affect the ability to bind and deteriorate the pRB, but they do abrogate its ability to immortalize cells (79). In the human papillomavirus 83 (HPV83m) that produced cervical cancer, five mutations were found in the second zinc finger domain of E6, an important domain for protein-protein or protein-DNA interactions. These mutations do not disrupt the p53 stability or telomerase activity, and they act only as a specific modulator of the transcriptional machinery. The mutation in the second zinc finger can increase the oncogenic potential of HPV83 (80).

The pCAF acetyltransferase is a co-activator for a variety of transcription factors including p53. An interaction of the HPV 6, 16 and 18 E7 proteins with pCAF acetyltransferase has been described (81). Mutation of a highly conserved leucine residue within the zinc finger region of HPV 16 E7 
disrupts binding to pCAF and impairs transformation and transcriptional activation (81).

Mino et al have constructed, as candidates for new antiviral drugs, cell-permeable artificial zinc finger proteins (AZPs), namely PTD-4 AZP, AZP-R9, AZPAla-R9 and E2C-R9, for inhibition of HPV-18 DNA replication (82). The AZP used in this study is the one that reduced the replication level of HPV 18 DNA to $12 \%$ of that of a control. They confirmed that cell-permeable AZPs are effective for inhibition of the HPV replication (82). Artificial zinc fingers (AZF) have been designed as potent new inhibitors of HPV, thus, they block the replication in episomal HPV infection, hindering the union of E2 to origin of the viral replication (83). The avian papillomavirus (PV) share with the mammalian PV strictly conserved ORFs in E1, E2, L1 and L2 proteins (84). The differences of avian PV from the mammalian PV is that avian E7 protein contain an extended unfolded $\mathrm{N}$-terminus and a zinc-binding domain of reduced size, and the avian E6 proteins consist of a single zinc-binding domain, whereas all mammalian E6 proteins always contain a pair of zinc-binding domains (85). One hypothesis suggests that it could be one common PV-single zinc-binding domain ancestor and that the duplication event may have taken place during the 310 million years separating birds and mammals (86). A direct interaction has been demonstrated between the HPV E2 and E7 proteins. It requires the hinge region of $\mathrm{E} 2$ and the zinc-binding domain of E7. E2 is responsible for the stability of E7 and its cellular location during mitosis (87). Mavromatis et al have shown that the part carboxyl-terminus of human papillomavirus (HPV) E7 oncoprotein can be replaced by the zinc-binding domains of the HPV E6 protein. This part is necessary for the functional and structural integrity of the HPV (78).

\section{Metallothionein in head and neck cancer}

Metallothioneins (MT) are low-molecular weight proteins involved in heavy metal detoxification, essential metal ion homeostasis and cell protection against free radicals (88-92). Several studies reported increased MT protein levels in malignant tumors in head and neck area (93-95). Sochor et al determined MT levels in tumor tissues of patients suffering from head and neck tumors using differential pulse voltammetry (94). Fifty-five samples of tumor tissue were analyzed. The highest MT level was determined in the tissues of oral tumors $(170 \pm 70 \mu \mathrm{g} / \mathrm{g})$ followed by hypopharynx $(160 \pm 70 \mu \mathrm{g} / \mathrm{g})$ and larynx $(160 \pm 70 \mu \mathrm{g} / \mathrm{g})$. The relatively lowest MT level was determined in tumors of oropharynx $(130 \pm 50 \mu \mathrm{g} / \mathrm{g})$. In the following study, Krejcova et al analyzed MT levels in blood of patients suffering from primary malignant tumor in head and neck area also using differential pulse voltammetry (93). The tumor blood samples was represented by patients suffering from oropharyngeal cancer, laryngeal cancer, hypopharyngeal cancer, oral cavity cancer and rarely occurring nasal cavity and paranasal sinus cancer. The obtained data of MT level in blood of healthy human were from 0.2 to $0.8 \mu \mathrm{M}$. Determined MT levels in blood of oncological patients varied from 1.08 to $6.39 \mu \mathrm{M}$ (93). In the study of Dutsch-Wicherek et al, tissue samples taken from patients with pharyngeal squamous cell carcinoma were analyzed (96). An increased immunoreactivity levels of MT was observed in the tissue samples from tonsillar squamous cell carcinoma in comparison to reference group. Jayasurya et al examined the relationship between MT expression and tissue zinc levels in conjunction with cell proliferation in nasopharyngeal cancer (NPC) (97). Thirteen tumors displayed weak MT staining and the remaining 11 showed moderate to strong immunostaining. A linear relationship was also observed between nuclear zinc levels and MT immunostaining. In the next study Dutsch-Wicherek et al evaluated the MT expression using immunohistochemistry in head and neck squamous cells carcinoma and its histologically healthy adjacent tissue (98). MT expression was revealed in $85.7 \%$ of head and neck cancers and MT expression was statistically significantly higher in tumor adjacent tissue than in cancer tissue in cases with the presence of lymph node metastases. Therefore, it can be concluded that the increased MT expression is observed in tumor tissues as well as in blood of patients with head and neck cancers.

\section{Zinc, zinc fingers, p53 and metallothionein - is there any connection with HPV?}

Zinc is an essential element that controls the normal development of the cells, tissues, and organs via zinc-containing proteins that orchestrate cell genesis, differentiation and viability $(99,100)$. Many transcriptional factors contain zinc finger motifs. Zinc finger is able to form a complex with DNA based on the interactions between $\alpha$-helix of a zinc finger and DNA-specific bases. The function of the zinc fingers consists especially in the recognition of DNA and the activation of transcriptional processes. Role of the zinc finger proteins in the regulating the cell proliferation by HPV is described above. On the other hand, p53 is a transcription factor encoded by the tumor suppressor gene TP53 that binds DNA via structurally complex domain stabilized by a zinc atom (101). Genotoxic as well as non-genotoxic stress induce p53 and coordinate pro-apoptotic (anti-proliferative) pathways to eliminate cells with damaged DNA. The depletion of the intracellular zinc can induce a change in the p53 protein conformation and the loss of DNA binding capacity (101). The role of metallothionein in the controlling the conformation and activity of the p53 protein is still discussed $(102,103)$. The intracellular level of zinc(II) ions is strictly regulated in cells. Metallothionein (MT), a family of proteins rich on cysteine residues, plays a key role in the regulating the intracellular zinc levels and distribution $(88,89)$. MT is localized especially to the membrane of the Golgi apparatus. On the other hand, Tohyama et al (104) and Tsujikawa et al (105) have shown presence of MT in nuclei of hepatocytes, Nartey et al in fetal human liver and kidney (106), and Banerjee et al in nuclei of rat liver and kidney (107). Tohno et al have characterized MT-binding chromatin after induction by 4-aminopyrazolo[3,4-d] pyrimidine (108). The MT-binding chromatin was composed of supranucleosomal fibers. Localization of MT in myotomal cell nuclei during somitogenesis of Xenopus laevis has been described by Sunderman et al (109). These authors observed not only presence of MT, but also its increasing after exposure to zinc(II) ions. This fact indicates involvement of MT in the regulation of the cell genesis, proliferation and viability. In light of these facts, we must assume the role of metallothionein in the regulation of transcription in HPV-infected cells via zinc(II) ions. Closer 
information is unfortunately still lacking and further research to determine the possible connection in the involvement of MT and zinc(II) ions in HPV infection and regulation of the cell proliferation and viability is necessary.

\section{Acknowledgements}

Financial support from SPINCANCER NT/14337 and CEITEC CZ.1.05/1.1.00/02.0068 is highly acknowledged.

\section{References}

1. Stanley M: Pathology and epidemiology of HPV infection in females. Gynecol Oncol 117: S5-S10, 2010.

2. Lowy DR, Strickland JE and Yuspa SH: Efficient induction of papillomas by Harvey murine sarcoma-virus. Clin Res 34: A764, 1986.

3. Joh J, Jenson AB, Proctor M, et al: Molecular diagnosis of a laboratory mouse papillomavirus (MusPV). Exp Mol Pathol 93: 416-421, 2012.

4. Mitsouras K, Faulhaber EA, Hui G, et al: Development of a PCR assay to detect papillomavirus infection in the snow leopard. BMC Vet Res 7: 1-11, 2011.

5. Badulescu F, Crisan A, Badulescu A and Schenker M: Recent data about the role of human papillomavirus (HPV) in oncogenesis of head and neck cancer. Rom J Morphol Embryol 51: 437-440, 2010.

6. Fakhry C, Westra WH, Cmelak SLA, et al: Improved survival of patients with human papillomavirus-positive head and neck squamous cell carcinoma in a prospective clinical trial. J Nat Cancer Inst 100: 261-269, 2008.

7. Syrjanen S: Human papillomavirus (HPV) in head and neck cancer. J Clin Virol 32: S59-S66, 2005.

8. Walden MJ and Aygun N: Head and neck cancer. Semin Roentgenol 48: 75-86, 2013.

9. Forte T, Niu J, Lockwood GA and Bryant HE: Incidence trends in head and neck cancers and human papillomavirus (HPV)-associated oropharyngeal cancer in Canada, 1992-2009. Cancer Causes Control 23: 1343-1348, 2012.

10. Axell T, Pindborg JJ, Smith CJ and van der Waal I: Oral white lesions with special reference to precancerous and tobacco related lesions: conclusions of an international symposium held in Uppsala, Sweden, May 18-21 1994. J Oral Pathol Med 25: 49-54, 1996.

11. Janicek MF and Averette HE: Cervical cancer: prevention, diagnosis, and therapeutics. CA Cancer J Clin 51: 92-114, 2001.

12. Chen YC and Hunter DJ: Molecular epidemiology of cancer CA Cancer J Clin 55: 45-54, 2005.

13. De Villiers EM, Fauquet C, Broker TR, Bernard HU and zur Hausen H: Classification of papillomaviruses. Virology 324: 17-27, 2004

14. Bernard HU, Burk RD, Chen ZG, van Doorslaer K, zur Hausen H and de Villiers EM: Classification of papillomaviruses (PVs) based on $189 \mathrm{PV}$ types and proposal of taxonomic amendments. Virology 401: 70-79, 2010.

15. Doorbar J, Quint W, Banks L, et al: The biology and life-cycle of human papillomaviruses. Vaccine 30: F55-F70, 2012.

16. Chen RW, Aaltonen LM and Vaheri A: Human papillomavirus type 16 in head and neck carcinogenesis. Rev Med Virol 15 351-363, 2005.

17. Pfister H: HPV and skin neoplasia. Hautarzt 59: 26-30, 2008 (In German).

18. Steben $M$ and Duarte-Franco E: Human papillomavirus infection: epidemiology and pathophysiology. Gynecol Oncol 107: S2-S5, 2007.

19. Chang KC, Su IJ, Tsai ST, Shieh DB and Jin YT: Pathological features of betel quid-related oral epithelial lesions in Taiwan with special emphasis on the tumor progression and human papillomavirus association. Oncology 63: 362-369, 2002.

20. Kero K, Rautava J, Syrjanen K, Grenman S and Syrjanen S: Oral mucosa as a reservoir of human papillomavirus: point prevalence, genotype distribution, and incident infections among males in a 7-year prospective study. Eur Urol 62: 1063-1070, 2012.

21. Hong AM, Martin A, Armstrong BK, et al: Human papillomavirus modifies the prognostic significance of T stage and possibly $\mathrm{N}$ stage in tonsillar cancer. Ann Oncol 24: 215-219, 2013.
22. Milano MT, Peterson CR, Zhang H, Singh DP and Chen Y: Second primary lung cancer after head and neck squamous cell cancer: population-based study of risk factors. Head Neck 34 : $1782-1788,2012$

23. Ragin CCR and Taioli E: Survival of squamous cell carcinoma of the head and neck in relation to human papillomavirus infection: review and meta-analysis. Int J Cancer 121: 1813-1820, 2007

24. Lin KY, Westra WH, Kashima HK, Mounts P and Wu TC: Coinfection of HPV-11 and HPV-16 in a case of laryngeal squamous papillomas with severe dysplasia. Laryngoscope 107: 942-947, 1997.

25. Syrjanen KJ, Chang F and Syrjanen SM: HPV infections in etiology of benign and malignant sinonasal, bronchial and oesophageal squamous cell lesions. In: Eurogin 2000: 4th International Multidisciplinary Congress. Monsonego J (ed). Medimond S R L: 40128 Bologna, pp169-179, 2000.

26. Hoffmann M, Klose N, Gottschlich S, et al: Detection of human papillomavirus DNA in benign and malignant sinonasal neoplasms. Cancer Lett 239: 64-70, 2006.

27. Syrjanen S: Human papillomavirus infections and oral tumors. Med Microbiol Immunol 192: 123-128, 2003

28. Kashima HK, Kessis T, Hruban RH, Wu TC, Zinreich SJ and Shah KV: Human papilloma virus in sinonasal papillomas and squamous-cell carcinoma. Laryngoscope 102: 973-976, 1992

29. Mansell NJ and Bates GJ: The inverted Schneiderian papilloma: a review and literature report of 43 new cases. Rhinology 38: 97-101, 2000

30. Zandberg DP, Bhargava R, Badin S and Cullen KJ: The role of human papillomavirus in nongenital cancers. CA Cancer J Clin 63: $57-81,2013$

31. Ustav M, Ustav E, Szymanski P and Stenlund A: Identification of the origin of replication of bovine papillomavirus and characterization of the viral origin recognition factor-E1. EMBO J 10: 4321-4329, 1991.

32. Baker CC, Phelps WC, Lindgren V, Braun MJ, Gonda MA and Howley PM: Structural and transcriptional analysis of human papillomavirus type-16 sequences in cervical-carcinoma cell-lines. J Virol 61: 962-971, 1987.

33. Bouvard V, Storey A, Pim D and Banks L: Characterization of the human papillomavirus E2 protein - evidence of transactivation and transrepression in cervical keratinocytes. EMBO J 13: 5451-5459, 1994.

34. Foguel D, Silva JL and de Prat-Gay G: Characterization of a partially folded monomer of the DNA-binding domain of human papillomavirus E2 protein obtained at high pressure. J Biol Chem 273: 9050-9057, 1998

35. Zur Hausen H: Cervical carcinoma and human papillomavirus: on the road to preventing a major human cancer. J Natl Cancer Inst 93: 252-253, 2001

36. Barbosa MS, Lowy DR and Schiller JT: Papillomavirus polypeptide-E6 and polypeptide-E7 are zinc-binding proteins. J Virol 63: 1404-1407, 1989.

37. Scheffner M, Werness BA, Huibregtse JM, Levine AJ and Howley PM: The E6 oncoprotein encoded by human papillomavirus type-16 and type-18 promotes the degradation of P53. Cell 63: 1129-1136, 1990

38. Vega-Pena A, Illades-Aguiar B, Flores-Alfaro E, LopezBayghen E, Reyes-Maldonado E and Alarcon-Romero LD: Correlation between KI-67 and telomerase expression with in situ hybridization for high-risk human papillomavirus. Arch Biol Sci 65: 81-90, 2013.

39. Li DS, Dong BL, Hu ZM, et al: A combined assay of hTERT and E6 oncoprotein to identify virus-infected keratinocytes with higher telomerase activity in human papillomaviruses 16 and 18-related bowenoid papulosis. Am J Dermatopathol 34: 813-817, 2012

40. Zhao YX, Qi L, Chen F, Zhao Y and Fan CH: Highly sensitive detection of telomerase activity in tumor cells by cascade isothermal signal amplification based on three-way junction and base-stacking hybridization. Biosens Bioelectron 41: 764-770, 2013.

41. Wilting SM, Verlaat W, Jaspers A, et al: Methylation-mediated transcriptional repression of microRNAs during cervical carcinogenesis. Epigenetics 8: 220-228, 2013.

42. Dayyani F, Etzel CJ, Liu M, Ho CH, Lippman SM and Tsao AS Meta-analysis of the impact of human papillomavirus (HPV) on cancer risk and overall survival in head and neck squamous cell carcinomas (HNSCC). Head Neck Oncol 2: 1-11, 2010.

43. Dyson N, Howley PM, Munger K and Harlow E: The human papilloma virus-16 E7-oncoprotein is able to bind to the retinoblastoma gene-product. Science 243: 934-937, 1989. 
44. Strati K, Pitot HC and Lambert PF: Identification of biomarker that distinguish human papillomavirus (HPV)-positive versus HPV-negative head and neck cancers in a mouse model. Proc Natl Acad Sci USA 103: 14152-14157, 2006.

45. Smith EM, Pawlita M, Rubenstein LM, Haugen TH, Hamsikova E and Turek LP: Risk factors and survival by HPV-16 E6 and E7 antibody status in human papillomavirus positive head and neck cancer. Int J Cancer 127: 111-117, 2010.

46. Doorbar J and Gallimore PH: Identification of proteins encoded by the L1 and L2 open reading frames of human papillomavirus 1a. J Virol 61: 2793-2799, 1987.

47. Rose BR, Thompson CH, Tattersall MH, O'Brien CJ and Cossart YE: Squamous carcinoma of the head and neck: molecular mechanisms and potential biomarkers. Aust N Z J Surg 70: 601-606, 2000.

48. Wiest T, Schwarz E, Enders C, Flechtenmacher C and Bosch FX: Involvement of intact HPV16 E6/E7 gene expression in head and neck cancers with unaltered p53 status and perturbed $\mathrm{pRb}$ cell cycle control. Oncogene 21: 1510-1517, 2002.

49. Bedell MA, Jones KH and Laimins LA: The E6-E7 region of human papillomavirus type-18 is sufficient for transformation of NIH-3T3 and RAT-1 cells. J Virol 61: 3635-3640, 1987.

50. Choo KB, Pan CC and Han SH: Integration of human papillomavirus type-16 into cellular DNA of cervicalcarcinoma-preferential deletion of the E2 gene and invariable retention of the long control region and the E6/E7 open reading frames. Virology 161: 259-261, 1987.

51. Huibregtse JM, Scheffner M and Howley PM: Cloning and expression of the cDNA for E6-AP, a protein that mediates the interaction of the human papillomavirus E6 oncoprotein with P53. Mol Cell Biol 13: 775-784, 1993.

52. Chellappan S, Kraus VB, Kroger B, et al: Adenovirus-E1A simian virus-40 tumor-antigen, and human papillomavirus-E7 protein share the capacity to disrupt the interaction between transcription factor-E2F and the retinoblastoma gene-product. Proc Natl Acad Sci USA 89: 4549-4553, 1992.

53. Cobrinik D, Dowdy SF, Hinds PW, Mittnacht S and Weinberg RA: The retinoblastoma protein and the regulation of cell cycling. Trends Biochem Sci 17: 312-315, 1992

54. Nevins JR: E2F - a link between the Rb tumor suppressor protein and viral oncoproteins. Science 258: 424-429, 1992.

55. Gillison ML, Koch WM, Capone RB, et al: Evidence for a causal association between human papillomavirus and a subset of head and neck cancers. J Natl Cancer Inst 92: 709-720, 2000.

56. May P and May E: Twenty years of p53 research: structural and functional aspects of the p53 protein. Oncogene 18: 7621-7636, 1999.

57. Yu ZK, Geyer RK and Maki CG: MDM2-dependent ubiquitination of nuclear and cytoplasmic P53. Oncogene 19: 5892-5897, 2000.

58. Haupt Y, Maya R, Kazaz A and Oren M: Mdm2 promotes the rapid degradation of p53. Nature 387: 296-299, 1997.

59. Huibregtse JM, Scheffner M and Howley PM: A cellular protein mediates association of P53 with the E6 oncoprotein of human papillomavirus type-16 or type-18. EMBO J 10: 4129-4135, 1991.

60. Chen JJ, Hong YH, Rustamzadeh E, Baleja JD and Androphy EJ: Identification of an alpha helical motif sufficient for association with papillomavirus E6. J Biol Chem 273: 13537-13544, 1998.

61. Elston RC, Napthine S and Doorbar J: The identification of a conserved binding motif within human papillomavirus type $16 \mathrm{E} 6$ binding peptides, E6AP and E6BP. J Gen Virol 79: 371-374, 1998.

62. Huibregtse JM, Scheffner M and Howley PM: Localization of the E6-AP regions that direct human papillomavirus E6 binding, association with P53, and ubiquitination of associated proteins Mol Cell Biol 13: 4918-4927, 1993

63. Yu Y, Yang AM, Hu SK, Zhang JH and Yan H: Significance of human papillomavirus $16 / 18$ infection in association with p53 mutation in lung carcinomas. Clin Respir J 7: 27-33, 2013.

64. Katori H, Nozawa A and Tsukuda M: Relationship between p21 and p53 expression, human papilloma virus infection and malignant transformation in sinonasal-inverted papilloma. Clin Oncol 18: 300-305, 2006

65. Fujita S, Senba M, Kumatori A, Hayashi T, Ikeda T and Toriyama K: Human papillomavirus infection in oral verrucous carcinoma: genotyping analysis and inverse correlation with p53 expression. Pathobiology 75: 257-264, 2008.

66. Reschner A, Bontems S, Le Gac S, et al: Ruthenium oligonucleotides, targeting HPV16 E6 oncogene, inhibit the growth of cervical cancer cells under illumination by a mechanism involving p53. Gene Ther 20: 435-443, 2013.
67. Togtema M, Pichardo S, Jackson R, Lambert PF, Curiel L and Zehbe I: Sonoporation delivery of monoclonal antibodies against human papillomavirus 16 E6 restores p53 expression in transformed cervical keratinocytes. PLoS One 7: 1-12, 2012.

68. Habbous S, Pang V, Eng L, et al: p53 Arg72Pro polymorphism, HPV status and initiation, progression, and development of cervical cancer: a systematic review and meta-analysis. Clin Cancer Res 18: 6407-6415, 2012.

69. Chen SP, Hsu NY, Wu JY, et al: Association of p53 codon 72 genotypes and clinical outcome in human papillomavirusinfected lung cancer patients. Ann Thorac Surg 95: 1196-1203, 2013.

70. Grossman SR and Laimins LA: E6-protein of human papillomavirus type-18 binds zinc. Oncogene 4: 1089-1093, 1989.

71. Kanda T, Watanabe S, Zanma S, Sato H, Furuno A and Yoshiike K: Human papillomavirus type-16 E6 proteins with glycine substitution for cysteine in the metal-binding motif. Virology 185: 536-543, 1991.

72. Beerheide W, Bernard HU, Tan YJ, Ganesan A, Rice WG and Ting AE: Potential drugs against cervical cancer: zinc-ejecting inhibitors of the human papillomavirus type 16 E6 oncoprotein. J Natl Cancer Inst 91: 1211-1220, 1999.

73. Chan SY, Delius H, Halpern AL and Bernard HU: Analysis of genomic sequences of 95 papillomavirus types - uniting typing, phylogeny, and taxonomy. J Virol 69: 3074-3083, 1995.

74. Ullman CG, Haris PI, Galloway DA, Emery VC and Perkins SJ: Predicted alpha-helix/beta-sheet secondary structures for the zinc-binding motifs of human papillomavirus E7 and E6 proteins by consensus prediction averaging and spectroscopic studies of E7. Biochem J 319: 229-239, 1996.

75. Griffin H, Elston R, Jackson D, et al: Inhibition of papillomavirus protein function in cervical cancer cells by intrabody targeting. J Mol Biol 355: 360-378, 2006.

76. Zimmermann H, Degenkolbe R, Bernard HU and O'Connor MJ: The human papillomavirus type 16 E6 oncoprotein can downregulate $\mathrm{p} 53$ activity by targeting the transcriptional coactivator CBP/p300. J Virol 73: 6209-6219, 1999.

77. Jong JE, Jeong KW, Shin H, Hwang LR, Lee D and Seo T: Human papillomavirus type 16 E6 protein inhibits DNA fragmentation via interaction with DNA fragmentation factor 40 . Cancer Lett 324: 109-117, 2012.

78. Mavromatis KO, Jones DL, Mukherjee R, Yee C, Grace M and Munger K: The carboxyl-terminal zinc-binding domain of the human papillomavirus E7 protein can be functionally replaced by the homologous sequences of the E6 protein. Virus Res 52: $109-118,1997$.

79. Wayengera M: Zinc finger arrays binding human papillomavirus types 16 and 18 genomic DNA: precursors of gene-therapeutics for in-situ reversal of associated cervical neoplasia. Theor Biol Med Model 9: 1-13, 2012.

80. Cannavo I, Benchetrit M, Loubatier C, Michel G, Lemichez E and Giordanengo V: Characterization of a cluster of oncogenic mutations in E6 of a human papillomavirus 83 variant isolated from a high-grade squamous intraepithelial lesion. J Gen Virol 92: 2428-2436, 2011

81. Avvakumov $\mathbf{N}$, Torchia $\mathbf{J}$ and Mymryk JS: Interaction of the HPV E7 proteins with the pCAF acetyltransferase. Oncogene 22: 3833-3841, 2003

82. Mino T, Mori T, Aoyama Y and Sera T: Cell-permeable artificial zinc-finger proteins as potent antiviral drugs for human papillomaviruses. Arch Virol 153: 1291-1298, 2008.

83. Olthof NC, Straetmans J, Snoeck R, Ramaekers FCS, Kremer B and Speel EJM: Next-generation treatment strategies for human papillomavirus-related head and neck squamous cell carcinoma: where do we go? Rev Med Virol 22: 88-105, 2012

84. Garcia-Vallve S, Alonso A and Bravo IG: Papillomaviruses: different genes have different histories. Trends Microbiol 13: 514-521, 2005

85. Van Doorslaer K, Sidi A, Zanier K, et al: Identification of unusual E6 and E7 proteins within avian papillomaviruses: cellular localization, biophysical characterization, and phylogenetic analysis. J Virol 83: 8759-8770, 2009.

86. Cole ST and Danos O: Nucleotide-sequence and comparativeanalysis of the human papillomavirus type 18 genome. Phylogeny of papillomaviruses and repeated structure of the E6 and E7 gene products. J Mol Biol 193: 599-608, 1987.

87. Gammoh N, Grm HS, Massimi P and Banks L: Regulation of human papillomavirus type 16 E7 activity through direct protein interaction with the E2 transcriptional activator. J Virol 80: 1787-1797, 2006 
88. Ruttkay-Nedecky B, Nejdl L, Gumulec J, et al: The role of metallothionein in oxidative stress. Int J Mol Sci 14: 6044-6066, 2013.

89. Krizkova S, Ryvolova M, Hrabeta J, et al: Metallothioneins and zinc in cancer diagnosis and therapy. Drug Metab Rev 44: 287-301, 2012.

90. Eckschlager T, Adam V, Hrabeta J, Figova K and Kizek R: Metallothioneins and cancer. Curr Protein Pept Sci 10: 360-375, 2009.

91. Krizkova S, Fabrik I, Adam V, Hrabeta J, Eckschlager T and Kizek R: Metallothionein - a promising tool for cancer diagnostics. Bratisl Lek Listy 110: 93-97, 2009.

92. Babula P, Masarik M, Adam V, et al: Mammalians' metallothioneins and their properties and functions. Metallomics 4 : $739-750,2012$

93. Krejcova L, Fabrik I, Hynek D, et al: Metallothionein electrochemically determined using Brdicka reaction as a promising blood marker of head and neck malignant tumours. Int $J$ Electrochem Sci 7: 1767-1784, 2012.

94. Sochor J, Hynek D, Krejcova L, et al: Study of metallothionein role in spinocellular carcinoma tissues of head and neck tumours using Brdicka reaction. Int J Electrochem Sci 7: 2136-2152, 2012.

95. Masarik M, Cernei N, Majzlik P, et al: Level of metallothionein, glutathione and heat-stable proteins in tumours from patients with head and neck cancer. Int J Mol Med 26: S46, 2010.

96. Dutsch-Wicherek M, Lazar A, Tomaszewska R, Kazmierczak W and Wicherek L: Analysis of metallothionein and vimentin immunoreactivity in pharyngeal squamous cell carcinoma and its microenvironment. Cell Tissue Res 352: 341-349, 2013.

97. Jayasurya A, Bay BH, Yap WM, Tan NG and Tan BKH: Proliferative potential in nasopharyngeal carcinoma: correlations with metallothionein expression and tissue zinc levels. Carcinogenesis 21: 1809-1812, 2000

98. Dutsch-Wicherek M, Popiela TJ, Klimek M, et al: Metallothionein stroma reaction in tumor adjacent healthy tissue in head and neck squamous cell carcinoma and breast adenocarcinoma. Neuroendocrinol Lett 26: 567-574, 2005.

99. Babula P, Kohoutkova V, Opatrilova R, Dankova I, Masarik M and Kizek R: Pharmaceutical importance of zinc and metallothionein in cell signalling. Chim Oggi-Chem Today 28: 18-21, 2010.
100. Gumulec J, Masarik M, Krizkova S, et al: Insight to physiology and pathology of zinc(II) ions and their actions in breast and prostate carcinoma. Curr Med Chem 18: 5041-5051, 2011.

101. Meplan C, Richard MJ and Hainaut P: Metalloregulation of the tumor suppressor protein $\mathrm{p} 53$ : zinc mediates the renaturation of p53 after exposure to metal chelators in vitro and in intact cells. Oncogene 19: 5227-5236, 2000.

102. Hainaut $\mathrm{P}$ and Mann K: Zinc binding and redox control of p53 structure and function. Antioxid Redox Signal 3: 611-623, 2001.

103. Pintus SS, Ivanisenko NV, Demenkov PS, et al: The substitutions $\mathrm{G} 245 \mathrm{C}$ and G245D in the $\mathrm{Zn}^{2+}$-binding pocket of the p53 protein result in differences of conformational flexibility of the DNA-binding domain. J Biomol Struct Dyn 31: $78-86,2013$

104. Tohyama C, Suzuki JS, Hemelraad J, Nishimura N and Nishimura $\mathrm{H}$ : Induction of metallothionein and its localization in the nucleus of rat hepatocytes after partial-hepatectomy. Hepatology 18: 1193-1201, 1993.

105. Tsujikawa K, Imai T, Kakutani M, et al: Localization of metallothionein in nuclei of growing primary cultured adult-rat hepatocytes. FEBS Lett 283: 239-242, 1991.

106. Nartey NO, Banerjee D and Cherian MG: Immunohistochemical localization of metallothionein in cell-nucleus and cytoplasm of fetal human-liver and kidney and its changes during development. Pathology 19: 233-238, 1987.

107. Banerjee D, Onosaka S and Cherian MG: Immunohistochemical localization of metallothionein in cell-nucleus and cytoplasm of rat-liver and kidney. Toxicology 24: 95-105, 1982.

108. Tohno Y, Tohno S, Minami T, et al: Bindings of metallothionein to supranucleosomal fibers in mouse pancreatic nuclei after induction by 4 -aminopyrazolo $[3,4-\mathrm{d}]$ pyrimidine. Cell Mol Biol 42: 1121-1127, 1996.

109. Sunderman FW, GrbacIvankovic S, Plowman MR and Davis $\mathrm{M}: \mathrm{Zn}^{2+}$-induction of metallothionein in myotomal cell nuclei during somitogenesis of Xenopus laevis. Mol Reprod Dev 43: 444-451, 1996.

110. Bernard X, Robinson P, Nomine Y, et al: Proteasomal degradation of p53 by human papillomavirus E6 oncoprotein relies on the structural integrity of p53 core domain. PLoS One 6: 1-10, 2011 